\title{
PENGEMBANGAN MEDIA PEMBELAJARAN INTERAKTIF 5 PROJECTS FOR BEGINNER BERBASIS LECTORA INSPIRE 17 PADA MATA PELAJARAN DASAR ELEKTRONIKA DI SMK NEGERI 3 SINGARAJA
}

\author{
B. D. Juli Antara' ${ }^{1}$ A. Adiarta ${ }^{2}$ N. Santiyadnya ${ }^{3}$ \\ 1,2,3Prodi Pendidikan Teknik Elektro, Universitas Pendidikan Ganesha, Singaraja \\ e-mail: diasjuliantara251@gmail.com, agus.adiarta2@undiksha.ac.id, santiyadnya@undiksha.ac.id
}

\begin{abstract}
Abstrak
Tujuan penelitian ini adalah untuk 1) membuat desain media pembelajaran interaktif, 2) mengetahui tingkat kelayakan media pembelajaran interaktif, 3) mengetahui respon siswa terhadap media pembelajaran interaktif. Penelitian ini merupakan jenis penelitian Reseach and Development (R\&D). Berdasarkan hasil penelitian yang telah dilaksanakan, diperoleh beberapa hasil yaitu: (1) hasil akhir dari media pembelajaran interaktif 5 Projects for Beginner berbasis Lectora Inspire 17 pada mata pelajaran Dasar Elektronika di SMK Negeri 3 Singaraja berupa CD interaktif, (2) hasil dari uji ahli mendapatkan hasil persentase untuk ahli media $97,64 \%$ pada kualifikasi sangat layak dan hasil persentase untuk ahli materi 96,92\% kualifikasi sangat layak, (3) respon siswa mendapatkan hasil persentase untuk uji kelompok kecil $88,50 \%$ pada kualifikasi baik dan hasil persentase uji kelompok besar $91,02 \%$ pada kualifikasi sangat baik. Berdasarkan hasil yang didapatkan, maka Media Pembelajaran Interaktif 5 Projects for beginner Berbasis Lectora Inspire 17 Pada Mata Pelajaran Dasar Elektronika di SMK Negeri 3 Singaraja, layak digunakan sebagai media pembelajaran.
\end{abstract}

Kata kunci: Media pembelajaran interaktif, Lectora Inspire 17, Dasar Elektronika

\begin{abstract}
The purpose of this study was to 1) create an interactive learning media design, 2) determine the feasibility of interactive learning media, 3) determine students' responses to interactive learning media. This study is a research Reseach and Development $(R \& D)$. Based on the research that has been conducted, we obtain some results, namely: (1) the outcome of an interactive learning media 5 Projects for Beginner based Lectora Inspire 17 on the subjects of Basic Electronics at SMK Negeri 3 Singaraja in the form of an interactive $C D$, (2) the results of the expert test to get the percentage to $97.64 \%$ of media experts at very decent qualifications and the percentage of $96.92 \%$ for qualified subject matter experts are very decent, (3) the response of students to get the percentage for a small group of test $88,50 \%$ in both qualifying and the results of a large group of test percentage $91.02 \%$ on excellent qualifications. Based on the results, then the Interactive Learning Media 5 Projects for Lectora Inspire beginner Based Lesson 17 In Basic Electronics at SMK Negeri 3 Singaraja, fit for use as a medium of learning.
\end{abstract}

Keywords: Media interactive learning, Lectora Inspire 17, Basic Electronics

\section{Pendahuluan}

Pendidikan adalah pembelajaran pengetahuan, keterampilan, dan kebiasaan sekelompok orang yang diturunkan dari satu generasi ke generasi berikutnya melalui pengajaran, pelatihan, atau penelitian. Maju atau tidaknya sumber daya manusia ditentukan oleh pendidikan dan pengetahuan yang diterimanya. Bersasarkan UU No. 20 Tahun 2003, pendidikan adalah usaha sadar dan terencana untuk mewujudkan suasana belajar dan proses pembelajaran agar peserta didik secara aktif mengembangkan potensi dirinya untuk memiliki kekuatan spiritual keagamaan, pengendalian diri, kepribadian, kecerdasan, akhlak mulia, serta keterampilan yang diperlukan dirinya, masyarakat, bangsa dan negara. 
Perkembangan teknologi dan informasi membawa dampak kemajuan yang sangat pesat terhadap dunia pendidikan. Salah satu contoh penggunaan teknologi dalam dunia adalah memanfaatkan teknologi komputer. Teknologi komputer yang sering digunakan oleh guru dalam menyampaikan materi kepada siswa dan siswi adalah dengan menggunakan media pembelajaran.

Menurut undang - undang Sistem Pendidikan Nasional UU No. 20 Tahun 2003 menyatakan pembelajaran adalah "proses interaksi peserta didik dengan pendidik dan sumber belajar pada suatu lingkungan belajar". Pembelajaran tidak terlepas dari perangkat pembelajaran. Perangkat pembelajaran adalah sekumpulan media atau sarana yang digunakan oleh guru dan siswa dalam proses pembelajaran di kelas, serangkaian perangkat pembelajaran yang harus dipersiapkan seorang guru dalam menghadapi pembelajaran di kelas.

SMK Negeri 3 Singaraja merupakan salah satu sekolah yang mempunyai misi mencetak tenaga terampil dalam dasar elektronika. Pembelajaran yang menerangkan komponen dasar elektronika diperoleh dari mata pelejaran dasar elektronika dimana dalam mata pelejaran ini para siswa diharapkan mampu menguasai materi komponen dasar elektronika yang akan menjadi dasar atau tolak ukur untuk melanjutkan ke tingkat selanjutnya.

Berdasarkan hasil observasi dan wawancara dengan guru pengampu mata pelajaran dasar elektronika, kegiatan pembelajaran di kelas belum maksimal. Hal ini dikarenakan oleh beberapa faktor yaitu: 1) kurangnya minat dan semangat belajar siswa. 2) kurang maksimalnya media pembelajaran yang mengakibatkan pembelajaran belum maksimal. 3) pendidik yang belum menguasai materi secara maksimal. 4) metode pembelajaran yang digunakan masih metode ceramah dan media yang digunakan masih berupa power point saja. Berdasarkan uraian diatas, maka dikembangkan media pembelajaran interaktif 5 Projects for Beginner berbasis Lectora Inspire 17 pada mata pelajaran Dasar Elektronika dengan tujuan untuk memaksimalkan pembelajaran di kelas.

Dengan adanya media pembelajaran interaktif 5 Projects for Beginner berbasis Lectora Inspire 17 diharapkan dapat meningkatkan pengertian dan pemahaman siswa dalam mata pelajaran Dasar Elektronika. Sesuai dengan latar belakang dan juga perumusan masalah yang telah dipaparkan, jadi dapat diuraikan tujuan dari pengembangan ini adalah (1) untuk mengetahui tingkat kelayakan media pembelajaran interaktif berbasis lectora inspire 17 pada mata pelajaran dasar elektronika. (2) untuk mengetahui respon siswa terhadap media pembelajaran interakrif berbasis lectora inspire 17 pada mata pelajaran dasar elektronika.

\section{Metode}

Dari rumusan masalah dan tujuan penelitian penelitian yang telah dipaparkan dengan judul penelitian Pengembangan Media Pembelajaran Interaktif 5 Projects for Beginner Berbasis Lectora Inspire 17 Pada Mata Pelajaran Dasar Elektronika di Kelas X TAV di SMK Negeri Singaraja merupakan penelitian pengembangan (research and development) yaitu proses atau langkah - langkah dalam rangka mengembangkan suatu produk baru atau menyempurnakan produk yang telah ada agar dapat dipertanggung jawabkan. Produk tersebut tidak selalu berbentuk benda atau perangkat keras (hardware), seperti buku, modul, alat bantu pembelajaran di kelas atau di laboratorium, tetapi dapat juga perangkat lunak (software), seperti program komputer untuk pengolahan data, pembelajaran di kelas, perpustakaan atau laboratorium, ataupun model - model pendidikan, pembelajaran, pelatihan, bimbingan, dan evaluasi, sistem manajemen. (Trianto, 2010:206).

Pada penelitian ini menggunakan model pengembangan sugiyono, menurut sugiyono (2011: 409), ada 10 langkah - langkah dalam penelitian R\&Danatar lain: (1) Potensi dan Masalah, (2) Pengumpulan Data, (3) Desain Produk, (4) Validasi Desain, (5) Revisi Desain, (6) Uji coba produk, (7) Revisi Produk, (8) Uji Coba Pemakaian, (9) Revisi Produk, (10) Produksi Masal. 
Dalam penelitian ini, peneliti menguji produk pada subjek penelitian yaitu siswa kelas X TAV karena siswa kelas X mendapatkan mata pelajaran dasar elektronika. Metode pengumpulan data Perancangan yang disusun dalam penelitian ini adalah sebagai berikut. (1) Data Validasi Ahli dipeoleh dari lembar validasi yang diberikan kepada para ahli media dan materi untuk menilai dan menelaah media pembelajaran yang dikembangkan. Hasil telah digunakan sebagai masukan untuk merevisi/ menyempurnakan media pembelajaran interaktif yang digunakan. (2) Data Respon siswa, Untuk pengumpulan data dari respon siswa mengenai media pembelajaran interaktif yang di kembangkan dilakukan dengan metode angket.

Instrument penelitian atau alat yang digunakan untuk mengumpulkan data dalam suatu penelitian. 1) Lembar Validasi Media Pembelajaran, Instrumen ini digunakan untuk mendapatkan data mengenai pendapat para ahli (validator) terhadap media pembelajaran dikembangkan sehingga menjadi acuan/pedoman dalam merevisi media pembelajaran yang dikembangkan, yaitu instrumen uji kelayakan untuk ahli materi dan instrumen uji kelayakan untuk ahli media. 2) Lembar Angket Respon Siswa Instrumen ini disusun untuk mendapatkan data mengenai pendapat siswa terhadap materi dan media pembelajaran yang dikembangkan. Teknik Analisa data pada penelitian ini adalah dilakukan dengan analisis menggunakan teknik deskriptif presentase serta jenis data yang digunakan dalam penelitian ini adalah data kuantitatif. Dalam penilaian validasi media dilakukan dengan beberapa ktriteria yaitu sangat setuju, setuju, kurang setuju, tidak setuju, dan sangat tidak setuju. Dimana masing-masing item memiliki skor. Rentang persentase dan kriteria kualitatif uji kelayakan media dapat ditetapkan pada Tabel.

Tabel 1. Kualifikasi tingkat kelayakan berdasarkan presentase (Sugiyono, 2013:305)

\begin{tabular}{ccc}
\hline No & Interval & Kriteria \\
\hline 1 & $84,01 \%-100 \%$ & Sangat Layak \\
2 & $68,01 \%-84,00 \%$ & Layak \\
3 & $52,01 \%-68,00 \%$ & Cukup Layak \\
3 & $36,01 \%-52,00 \%$ & Kurang Layak \\
4 & $20,00 \%-36,00 \%$ & Tidak Layak \\
\hline
\end{tabular}

\section{Hasil dan Pembahasan}

Pengujian media pembelajaran yang telah dikembangkan peneliti dilakukan sebanyak empat kali. Pada tahap pertama dilakukan uji validasi media yang diisi oleh validator dari dosen Fakultas IImu Pendidikan yaitu Dr. I Made Tegeh, S.Pd., M.Pd setelah itu, tahap kedua uji validasi materi diisi oleh validator guru pengampu mata pelajaran Dasar Elektronika yaitu Luh Dita Widyastuti, S.Pd Tahap ketiga uji produk lapangan kelompok kecil yang dimana menggunakan siswa kelas X TAV-2 sebanyak 5 orang. Setelah mendapatkan respon dari pengujian kelompok kecil, maka tahap terakhir adalah melakukan pengujian kelompok besar, menggunakan 28 orang siswa kelas X TAV-2. Tujuan dari penelitian ini adalah (1) untuk mengetahui tingkat kelayakan media pembelajaran interaktif 5 Projects for Beginner yang dikembangkan peneliti. (2) untuk mengetahui respon siswa dengan media pembelajaran interaktif 5 Projects for Beginner untuk meningkatkan keterampilan dalam dasar elektronika.

Untuk penelitian tahap pertama dilakukan beberapa kegiatan yaitu (1) pengumpulan 
data (2) desain produ (3) validasi (4) revisi desain. Setelah dilakukannya tahap pertama, kemudian tahap selanjtunya, dilakukan pembuatan produk, setelah prdouk selesai maka akan dilakukan revisi produk yang telah dibuat sebelum diuji kelayakannya.

Tahap selanjutnya yaitu melakukan uji produk, yang dimana dilakukan sebanyak empat kali yaitu uji validasi ahli media, uji ahli materi, uji kelompok kecii dan uji kelompok besar. Perolehan presentase dari uji ahli media mendapat hasil 97,64\%. Hasil tersebut dikategorikan sangat layak dan ahli media memberikan masukkan yaitu penambahan sumber pada setiap gambar dan video yang ada pada media pembelajaaran interaktif. Perolehan presentase dari uji ahli materi yang langsung diisi oleh guru pengampu mata pelajaran dasar elektronika mendapat hasil 96,92\%. Hasil tersebut dikategorikan sangat layak untuk digunakan sebagai media pembelajaran pada mata pelajaran Dasar Elektronika.

Setelah melakukan pengujian validasi ahli media dan juga materi, maka selanjutnya dilakukan uji produk kelompok kecil. Dari uji kelompok kecil, media pembelajaran mendapatkan hasil $88,50 \%$ yang dimana hasil tersebut dikategorikan layak. Selanjutnya dilakukan uji produk pada kelompok besar. Pada kelompok besar mendapatkan hasil $91,02 \%$. Hasil tersebut dapat dikategorikan sangat layak untuk digunakan pada mata pelajaran Dasar Elektronika. Untuk hasil uji produk keseluruhan yang telah didapatkan dapat dilihat pada Tabel 2.

Tabel 2. Hasil

(Sumber: Hasil Pengamatan Sendiri)

\begin{tabular}{cccc}
\hline Uji & Total poin & $\%$ & Kreteria \\
\hline Uji Media & 144 & $97,64 \%$ & Sangat layak \\
Uji Materi & 90 & $96,92 \%$ & Sangat layak \\
Uji Kelompok kecil & 443 & $88,50 \%$ & Baik \\
Uji Kelompok Besar & 1446 & $91,02 \%$ & Sangat Baik \\
\hline
\end{tabular}

\section{Simpulan dan Saran}

Berdasarkan hasil dan pembahasan dapat disimpulkan hasil akhir dari media pembalajaran interaktif 5 Projects for Beginner berbasis Lectora Inspire 17 pada mata pelajaran Dasar Elektronika di SMK Negeri 3 Singaraja berupa CD interaktif, media pembalajaran interaktif 5 Projects for Beginner berbasis Lectora Inspire 17 pada mata pelajaran Dasar Elektronika di SMK Negeri 3 Singaraja layak digunakan sebagai media pembelajaran, serta dapat digunakan untuk membantu proses pembelajaran dan mendapat respon baik dari siswa. Hasil uji ahli media mendapatkan hasil persentase 96,92\% sangat layak, ahli materi mendapatkan hasil persentase $97.64 \%$ sangat layak, uji coba kelompok kecil mendapatkan hasil persentase $88,50 \%$ baik, uji coba kelompok besar mendapatkan hasil persentase $91,02 \%$ sangat baik.

Adapun saran yang di sampaikan yang berkaitan dengan penelitian pengembangan media pembelajaran interaktif 5 projects for beginner berbasis lectora inspire 17 pada mata pelajaran Dasar Elektronika yaitu sebagai berikut. Saran untuk siswa adalah agar menggunakan media pembelajaran interaktif 5 projects for beginner berbasis lectora inspire 17 pada mata pelajaran Dasar Elektronika sebagai media pendukung dalam pembelajaran. Saran bagi guru adalah media pemebelajaran interaktif 5 projects for beginner pada mata pelajaran Dasar Elektronika agar di terapkan lebih lanjut dalam proses pembelajaran di kelas sehingga dapat mencapai tujuan pembelajaran efektif dan efisien. 
Saran bagi kelapa sekolah adalah mengelola media pembelajaran interaktif 5 projects for beginner pada mata pelajaran Dasar Elektronika ini dengan baik, sebagai salah satu koleksi media pembelajaran yang dapat di manfaatkan oleh guru dan siswa. Saran untuk peneliti lain adalah untuk pengembangan media pembelajaran interaktif 5 projects for beginner mata pelajaran Dasar Elektronika nantinya agar menambahkan animasi rangkaian video simulasi dan video rangkain 5 projects for beginner yang peneliti sekarang belum bisa untuk mengembangkan karena keterbatasan waktu.

\section{Daftar Pustaka}

Achmad, Sugandi. 2000. Teori Pembelajaran. Bandung: PT. Remaja Rosdakarya.

AECT (Association for Educational Communication and Technology). 1976. Evaluating Media Programs District and School. Washington D.C: The Association.

Ahmadi, dkk. Ilmu Pendidikan. Jakarta: Rineka Cipta

Arsyad, Azhar. 2011. Media Pembelajaran. Jakarta: PT Raja Grafindo Persada.

Arsyad. 2005. Teknik Pengembangan Media. Jakarta: PT Raja Grafindo Persada.

Ariani, Haryanto. 2010. Pembelajaran Multimedia Di Sekolah. Jakarta: Prestasi Pustaka.

Arsy, Kusuma. 2015. Pembelajaran Matematika Menggunakan CD Interaktif AMT Berbasis Lectora Inspire Untuk Siswa SD. Semarang: Universitas PGRI.

Gerlach dan Ely. 1971. Teaching \& Media: A Systematic Approach. Second Edition, by V.S. Gerlach \& D.P. Ely, 1980, Boston, MA: Allyn dan Bacon. Copyright 1980 by Pearson Education.

Instructables Circuit. 2015. 10 Breadboard Projects for Beginners. (https://www.instructables.com/id/Ten-Breadboard-Projects-For-Beginners/), diakses 16 November 2018.

Mifhatul Huda. 2011. Efektifitas dan pengembangan media pembelajaran Teknologi Informasi dan Komunikasi berbasis multimedia pada materi Topologi Jaringan untuk SMA. Fakultas Teknik, Universitas Negeri Yogyakarta.

Mohammad Amin. 2009. Pengembangan Media Pembelajaran Teknik Kerja Membubut Ulir Berbasis Multimedia.

Mas'ud, Muhammad. 2012. Membuat Multimedia Pembelajaran Dengan Lectora. Yogyakarta: Pustaka shonif

Mbulu. 2004. Pengembangan Bahan Ajar. Malang: Elang Mas 
Munir. 2013. MULTIMEDIA dan Konsep Aplikasi Dalam Pendidikan. Bandung: Alfabeta National Education Association, (1969). Audiovisual Instruction Departemen, New Media and Collage Teaching. Washington, D.C: NEA

Narimawati, Umi. 2007. Riset Manajemen Sumber Daya Manusia. Jakarta: Agung Media.

Norma Dewi Shalikhah, dkk. 2016. Pengembangan Lembar Kerja Siswa. (tidak diterbitkan)

Norma Dewi Shalikhah, dkk. 2017. Media Pembelajaran Lectora Inspire. (tidak diterbitkan)

Suhardi. 2007. Perangkat Pembelajaran. Jakarta: Rineka Cipta

Santyasa, I Wayan. 2007. Landasan Konseptual Media Pembelajaran. Makalah Disajikan dalam Workshop Media Pembelajaran bagi Guru-Guru SMA Negeri Banjar Angkan Pada tanggal 10 Januari 2007 di Banjar Angkan Klungkung.

Suprapto dkk. 2006. Peningkatan Kualitas Pendidikan Melalui Media Pembelajaran Menggunakan Teknologi Informasi di Sekolah. Dalam Jurnal Ekonomi \& Pendidikan.

Sugiyono. 2009. Metode Penelitian Kuantitatif, Kualitatifdan R\&D, Bandung: Alfabeta.

Sugiyono. 2010. Statistika Untuk Penelitian. Bandung: Alfabeta.

Sugiyono. 2015. Metode Penelitian Pendidikan (Pendekatan Kualitatif, Kuantitatif, dan $R \& D)$. Bandung: Alfabeta.

Teknik Elektronika. 2014. Dasar Komponen Elektronika. (https://teknikelektronika.com/), diakses 16 November 2018

Wahono, R.S. 2006. Aspek dan Kriteria Penilaian Media Pembelajaran. RomiSatriaWohono.Net. (http://mustolihbrs.wordpress.com/2007/09/pengantarmedia- pembelajaran/), diakses 16 November 2018

Zainal Aqib. 2002. Professionalisme Guru DalamPembelajaran. Surabaya: Insan Cendikia.

Mestia Wendy Gustiariningsih, Ni Nyoman. 2015. "Evaluasi Pelaksanaan Sistem Informasi Kuliah Kerja Nyata (KKN) Menggunakan Metode CIPP (Context, Input, Process, Product) Study Kasus: Universitas Pendidikan Ganesha”. Skripsi [Tidak diterbitkan]. Universitas Pendidikan Ganesha.

Jurusan Teknik Elektro. 2016. "Katalog Prodi S1 Pendidikan Teknik Elektro Kurikulum KKNI". Singaraja. Prodi S1 Pendidikan Teknik Elektro

Sugiyono. 2015. "Metode penelitian pendidikan: Pendekatan kuantitatif, kualitatif, dan $R \& D$ ". Bandung: Alfabeta. 
Suharsaputra, U. 2012. "Metode penelitian kuantitatif, kualitatif, dan tindakan". Bandung: Refika Aditama.

Universitas Pendidikan Ganesha. 2012. Surat Keputusan Rektor Undiksha Nomor 610/UN.48/PP/2012 tentang Pedoman Studi. 